\title{
Student electives overseas: their value and some of the difficulties
}

\author{
RUTH A CRUIKSHANK, D B WALSH
}

The series of student elective articles that featured in the $B M F$ a few months ago prompted a review of electives within Dundee Medical School: the following figures, observations, and reflections may be of interest.

\section{International opportunities}

All medical schools in Britain provide for elective periods in their undergraduate curricula. Information gathered in 1974 showed that of the total number of students taking electives, the proportion spending the time abroad varied from $10-60 \%{ }^{1}$ Financial assistance, in the form of scholarships and other awards, is important, considering the high cost of air travel. Hubble $^{1}$ observed, however, that the variation in percentage seemed largely to depend on the degree of enthusiasm shown by staff and students. Enthusiasm has been reflected in the steadily increasing numbers of Dundee undergraduates in recent years who have chosen to spend short periods of elective study in other countries, some visiting the United States or Canada and others travelling to developing countries. In 1974-5 nine students from Dundee spent elective periods in North America, while 13 went to developing countries: by 1978-9 the corresponding figures were 11 and 31 . In these years the proportions of finalyear students studying overseas were $25 \%$ and $38 \%$ respectively. By the end of session 1979-80 the proportion is likely to be $60 \%$. Indications are that growing numbers of medical students will be attracted to overseas elective opportunities in the years ahead.

Medical schools abroad also include electives as an approved part of the undergraduate course, and increasing numbers of

Faculty of Medicine and Dentistry, University of Dundee, Ninewells Hospital and Medical School, Dundee DD1 9SY

RUTH A CRUIKSHANK, MA, secretary, electives office

D B WALSH, MRCPATH, adviser in studies applications are made for elective attachments in British medical schools. Since 1974, 156 medical students from 74 different medical schools ( 57 overseas) have spent short elective periods in Dundee. Elective applications from a further 250 students in various parts of the world were rejected because places were not available.

\section{Difficulties of organisation}

This international movement of senior clinical students is a recent development, and no real organisation has been set up to cope with it. The cumulative effect of medical students all over the world seeking electives outside the home university has created a force to be reckoned with. In most schools the students themselves are responsible for making their own arrangements. In Dundee this is beginning to cause problems, presumably not unique to our medical school. For example, heads of departments often make complex arrangements for study at the request of prospective "visiting students," only to have their programmes rejected in favour of acceptance elsewhere. There have been 122 such cancellations from students representing 64 medical schools (54 overseas) in the past five years. The situation gets worse as competition for elective places becomes keener: students adopt the practice of applying to many (not just several) medical schools to be assured of a place in one. With many students applying to mission hospitals in Third World countries (where their assistance is often a useful contribution), it would seem inevitable that doctors in these areas are involved in a multiplicity of correspondence with individual students.

One or two medical schools have taken organisation out of the hands of students, arrangements being made on their behalf by a faculty officer or head of department. This is much appreciated, as testimony of the status of the student is given and some assurance that an elective offered will be accepted. (Incidentally some hospitals overseas do not ask for verification of a student's status-a practice that could expose them to receiving fraudulent 
applications.) The Royal College of General Practitioners is understood to be looking into the organisation of electives as it affects departments of general practice. Is any other effort being made to find a solution?

The elective, and the option to spend this time in another country, is an important feature of the medical course in our universities for it provides access to a wide variety of patients and illnesses and allows the student to observe different approaches to health care. Within Britain tropical diseases are occurring more frequently as a result of the increased numbers of people travelling abroad and the increased speed of travelfor example, 62 cases of imported malaria in 1966; 1220 ten years later: this is one example among many to illustrate the practical value of undergraduate experience overseas.

An earlier view of the future of medical education ${ }^{2}$ seemed, in spirit, to favour the recent growth in electives and the freedom of choice they offer to each student. The elective venture is essentially forward-looking, containing within it the idea of the future. In the introduction to a series of books designed to prepare medical students for electives in other countries, overseas studies are placed firmly in global perspective: "New thrusts in health care are coming from sociocultural, economic, and political forces. Every country, whether old or new, developed or developing, rich or poor, is confronting problems surrounding the provision of medical sciences to its people. ..." "The commonality of the problems makes it essential that all nations work together in seeking solutions. No country has an unquestioned pre-eminence in the field; ideas and solutions may come from any quarter.",

Given the changing nature of society as well as the growth and shifts within medicine and patient care, some uncertainty and openness to persuasion are important characteristics for future doctors. ${ }^{4}$ Work overseas, where the student finds himself on unfamiliar ground, can do much to counter any tendency towards an insular or narrow-minded view of what society requires from medicine.

\section{Influence of the teacher}

Of all the influences on medical students, the personal qualities of the teacher must be one of the strongest. The influence of the clinical teacher has implications for creating the type of clinician a medical school or the medical profession wants to produce. ${ }^{5}$ Levine and Bonito ${ }^{6}$ noted that the start of the clinical years of training appears to be a critical point in the formation of the professional attitudes of new doctors. The elective provides opportunity for apprenticeship to a practitioner, who may be seen by the student as providing an example of good doctoring. It is important, therefore, to look closely at the nature and quality of apprenticeships, and give consideration to the people who are in this position of influence. In casting the net wide students are finding (perhaps looking for) a special type of direction and example.

For evidence it is unnecessary to look further than the elective reports that students write on return from abroad. These reports affirm more surely than any objective measure the value of such studies to the student. The recent student electives articles in the $B M F$ must surely have been welcomed by $\mathrm{Sir}$ George Pickering (and his followers), whose quest a few years ago found a scarcity of scholarship and literary opportunity among medical students. ${ }^{7}$ It is good news to know that a second series is being considered.

The future of international electives rests on the continued willingness of individual doctors, in all parts of the world and in all branches of medicine, to respond to requests from students who ask to study with them. The scale of the enterprise seems to call for firmer organisation.

How best to achieve this, while accommodating varying degrees of encouragement within medical schools and at the same time giving scope to the initiative of students, requires thought. It would help to compare experiences, discuss difficulties, explore possible developments. A solution might be found in sharing views.

\section{References}

${ }^{1}$ Hubble D. Electives in British medical schools. Update $1974 ; 8: 243-8$.

2 Goldberg A, ed. The future of medical education in Scotland. Edinburgh: Scottish Medical Journal, 1963.

${ }^{3}$ Cooper JAD. In : Joseph SC, Koch-Weser D, Wallace N, eds. International health perspectives. New York: Springer, 1977.

4 Fox R. Training for uncertainty. In: Merton R, Reader G, Kendall P, eds. The student-physician. Cambridge, Mass: Harvard University Press, 1957.

5 Gerber LA. The search for clinical role models as a way of coping with clerkship stress. F Med Educ 1979;54:659-61.

${ }^{6}$ Levine DM, Bonito AJ. Impact of clinical training on attitudes of medical students. Br $\mathcal{F}$ Med Educ 1974;8:13-6.

7 Pickering G. Quest for excellence in medical education: a personal survey. Oxford: Oxford University Press for the Nuffield Provincial Hospital Trust, 1978.
A patient of mine appears to be hypersensitive to local anaesthetics, pethidine, methadone (Physeptone), and possibly other opiates in that she becomes hypotensive with precordial pain and generally feels terrible for several days afterwards. If potent analgesics are required are there any other agents that are likely to be safer, and which local dental anaesthetic is least likely to produce this result?

All narcotic analgesics can produce hypotension and some patients, especially if elderly, are more sensitive to this effect than others. Of the narcotic analgesics available, pentazocine is the least likely to produce hypotension, but it is also a less effective analgesic than many of the others. Buprenorphine is a new, possibly more effective, narcotic analgesic, which is relatively free from cardiovascular side effects ${ }^{1}$ and would be worth trying in this patient. Hypotension during dental anaesthesia is usually a vasovagal response and is associated with bradycardia. ${ }^{3}$ Anaphylactoid (allergic) reactions to local anaesthetics are uncommon, and hypotension due to direct myocardial toxicity occurs only after excessive dosage or inadvertent intravenous injection of the anaesthetic. Allergic reactions are more likely to occur with the ester type of local anaesthetic (amethocaine, benzocaine, procaine) than with the amides (lignocaine, mepivacaine, prilocaine), but they have been reported with lignocaine. The vasovagal response is unrelated to the type of anaesthetic used. It can usually be prevented by premedication with atropine sulphate $600 \mathrm{mg}$ intravenously or with a sedative such as diazepam. ${ }^{3}$

1 Buprenorphine injection (Temgesic). Drug Ther Bull 1979;17:17-9. Cart DJ, Malcolm AD. Pharmacological and clinical importance of narcotic $1979 ; 7: 309-13 S$.

Yokobayashi T, Nakajima T, Yagata H, Yatabe Y. Changes of heart rate during 